\title{
Objecções contra a existencia do direito internacional publico
}

\author{
SUMMARIO \\ $\$ 1.0$ Base scientifica do direito. \\ § 2.0 Distincção entre a moral e o direito \\ $\S 3.0$ Primeira objecção: falta de poder legislativo. \\ $\S 4 .^{\circ}$ Segunda objecção: falta de poder judiciario. \\ §5.0 Terceira objecção: falta de sancção ou coacção \\ por parte do poder publico.
}

$$
\$ 1^{\circ}
$$

\section{Base scientitica do direito}

\section{AS DUAS CORRENTES OPPOSTAS}

Existe realmente um direito internacional? $\mathrm{O}$ conjuncto de principios e regras, a que se costuma dar este nome, não constituirá antes um systema puramente ethico ou moral, do que juridico?

Ha duas correntes entre os escriptores: uma responde que sim, a outra responde que não. Pertenço á primeira, que é pela existencia do direito internacional. A marcha evolutiva da sociedade dá-lhe dia a dia maior consistencia e vitalidade, ao passo que vai cada vez mais diminuindo a razão de ser da corrente opposta, que perde terreno progressivamente. A coexistencia harmonica dos estados na sociedade internacional é hoje um facto incontestavel e incontestado: $e$

Ubi societas, ibi jus. 


\section{BASE SCIENTIFICA DO DIREITO}

Conforme a doutrina exposta no $\S 110$ de meus Ensaios, o individuo, quer homern, quer estado, só vive e desenvolve-se na sociedade, segundo conhecida lei fundamental de sociologia calcada na observação dos factos.

Por outra face, a sociedade, quer dos homens, quer dos estados, só póde existir e desenvolver-se, restringindo cada um dos consociados a sua actividade, segundo outra lei fundamental de sociologia, de nós já conhecida.

Estas duas generalizações sociologicas constituem a base scientifica, em que assenta o direito. Este traça e mantém a linha divisoria das espheras de actividade das unidades sociaes, para que possa cada uma conservar-se e desenvolver-se, sem impedir que as outras façam o mesmo.

O direito é o factor da harmonia das espheras de actividade individual na coexistencia social. E' condição essencial á vida e desenvolvimento da sociedade e de suas unidades. Para que a sociedade dos estados se conserve e desenvolva, é condição imprescindivel que tenha cada estado uma esphera de acção, dentro da qual possa realizar tudo quanto the seja condição de vida e desenvolvimento, sem impedir os outros estados consociados de se conservarem e desenvolverem igualmente.

Constitué direito internacional todo o acto que é condição de vida e desenvolvimento para o estado, e cuja pratica não impossibilita a vida e desenvolvimento dos outros estados. As normas que asseguram a liberdade na realização dos actos dessa natureza são normas juridicas, e não meramente moraes.

\section{FONTES}

Para completa intelligencia desta parte da these, convém recordar ensinamentos que se encontram em meus Ensaios, indicados no indice alphabetico, "verbis: direito; escola scientifica; fundamento do direito; fun- 
damento da moral; moral; necessidade; necessidades sociaes; normas juridicas.

\section{$\S 2^{\circ}$.}

\section{Distinçăo entre a moral e o direito}

\section{Criterios intrinseco e extrinseco}

Com a materia do $\S 110$ dos Ensaios, que acabo de resumir, tem intima connexão a do seu $\$ 14$, que se inscreve:-- "Criterio intrinseco e criterio extrinseco da distincção entre a moral e o direito", e cuja leitura recommendo aos meus discipulos, porque esclarece muito o assumpto da these.

Quem bem souber extremar o direito da moral, por esta dualidade de criterios, o intrínseco, que é a gravidade do facto, e o extrinseco, que é a coacção por parte do poder publico, estará de posse de poderosa chave para a solução desta e de outras questões congeneres. Ahi nesse $\S 14$, verão que, si a norma é ou deve ser coactivamente assegurada pelo poder publico, em razão da gravidade do facto a que diz respeito, será norma de ordem juridica. moral.

No caso contrario, será norma exclusivamente

2. ACtividade hUmana inVoluntaria E VOluntaria

Melhor comprehenderá o conteúdo do mencionádo $\S 14$ quem bem conhecer a materia expendida no $\S$ 121, pags. $740-5$. em :

Ahi se verá que a actividade humana se divide

a) actividade involuntaria, que nada tem que vêr com o direito, e

b) actividade voluntaria, que é o factor dos actos que succedem á nossa volição.

A actividade voluntaria manifesta-se por duas ordens distinctas de actos: 
a) actos indifferentes, $\mathrm{e}$

b) actos que interessam o individuo, a sociedade e a especie, por dizerem respeito a sua conservação e desenvolvimento.

3. CONDUCTa, SUA NOÇÃO E DIVISÃo

O conjuncto destes actos queridos constitue a conducta lato sensu, que se define-

o conjuncto dos actos adaptados a um fim, ou a adaptação dos actos a fins.

A melhor conducta será a que melhor assegurar a vida e o desenvolvimento do individuo, da sociedade e da especie.

Nos ultimos estadios de sua evoluçào, assume a conducta o predicado de conducta ethica, comprehensiva da moral e do direito.

Póde-se, pois, dizer que ha tres circulos concentricos na conducta:

a) conducta em geral ou lato sensu,

b) conducta moral, e

c) conducta juridica.

O terceiro circulo se contém no segundo, como este no primeiro.

$O$ circulo juridico abrange os actos que são condições essenciaes de vida e desenvolvimento do indivividuo, da sociedade e da especie.

$\mathrm{O}$ circulo meramente moral abrange os actos que são condições, mas não essenciaes, de vida e desenvolvimento do individuo, da sociedade e da especie.

Os actos indifferentes pertencem ao circulo da conducta lato sensu.

A ethica ou moral em sentido amplo comprehende só os actos que interessam a vida e o desenvolvimento humano. Alguns destes actos, porém, são de tal importancia, exercem tal influencia sobre a conservação e progresso humano, que a sua pratica ou omissão é coisa da maior gravidade e exige que as respectivas 
normas, positivas ou negativas, sejam asseguradas ou garantidas pela força coercitiva do poder publico.

Estas ultimas normas é que constituem o direito. São as normas reguladoras da conducta juridica. A gravidade notada é o criterio intrinseco, e a coacção por parte do poder publico o criterio extrinseco da distịncção entre a moral (stricto sensu) e o direito.

\section{$\$ 3 .^{\circ}$}

\section{As TRES PRINCIPAES OBJECCÕES}

Isto posto, apreciemos succintamente as objecções que se tem formulado contra a existencia do direito internacional publico.

As principaes são tres, a saber:

a) falta de um congresso ou assembleia legislativa internacional, que formule as normas reguladoras da conducta juridica das unidades da communhão mundial;

b) falta de um poder judiciario que as applique aos casos concretos occorrentes no commercio juridico internacional ; e

c) falta de sancção ou coacção material.

Nenhuma destas objecções procede.

\section{Primelra obJecçá: falta de poder legislativo}

A primeira não procede, porque a lei não é a unica fonte ou orgam revelador do direito. Ha diversas outras fontes, como exponho no $\S 121$, pags. 745 e seguintes, dos meus Ensaios, cuja leitura recommendo por não alongar a exposição da these com a repetição do que alli vem expendido.

Não é o legislador que fez o direito interno, cuja existencia todos pacificamente reconhecem, mas, pelo contrario, foi este direito que $\mathrm{fez}$ o seu legislador. Esta verdade do direito interno o é tambem do direito externo ou internacional. 


\section{$-304-$ \\ $\$ 4 .^{\circ}$}

SEgUNDA OBJECÇÃO: FALTA DE PODER JUDICIARIO

A segunda tambem não procede, porquanto, esta falta de um orgam especial para applicar o direito aos casos concretos, dirimindo as contendas internacionaes, é um phenomeno natural, aliás de natureza provisoria, e não póde, por isso mesmo, destruir a natureza juridica, organica, fundamental e permanente do direito internacional. Si a objecção procedesse, o proprio direito interno deixaria a cada momento de ser direito, deante de innumeras e variadas circumstancias que, não raro, o tornam por completo inefficaz na pratica. $O$ direito fez o juiz, e não o juiz o direito, na vida de cada agrupamento social. O mesmo acontece, e deve acontecer, na sociedade dos estados: o direito internacional, que já existe, ha de crear opportunamente o magistrado internacional. E cumpre notar que as expostas objecções implicam o grave erro de presuppor que o orgam precede a funcção, quando é certo, pelo contrario, que a funcção é que precede o orgam.

\section{$\S 5 .^{\circ}$}

\section{Terceira objecção: falta de sancȩão ou coacção por parte do noder publico}

\section{O CONTEUdD DOS $§ \S 15$ E 16 REFUTA FSTA OBJECCÃO}

Não procede tão pouco esta ultima objecção formulada contra a existencia do direito internacional publico.

Este asserto é evidente, á vista do expedido nos precedentes $\S \S 15$ e 16.

\section{QUE É COACÇÃo?}

Cumpre saber o que seja coacção e qual a sua funcção no dynamismo juridico. Para disto conhecer-se quantum satis, basta que se recorde o que a respeito exponho nos Ensaios (nas passagens indicadas no indice alphabetico, v. coacção). 
3. Sociedade mundial implica DIREITO MUNDIAL

Como o individuo não póde viver e desenvolverse fóra da sociedade, tambem o estado não póde viver e desenvolver-se fóra da sociedade dos estados-sociedade das sociedades. Por outra face. como não póde a sociedade dos individuos subsistir e desenvolver-se, sem a restricção reciproca da actividade de cada individuo, assim tambem não póde a sociedade dos estados conseguir o mesmo fim, sinão medeante a mesma restricção, condição sine qua non de sua coexistencia harmonica na communhão mundial.

A existencia do direito internacional publico é, pois, uma inducção ineluctavel dos factos observados por toda a parte e em todas as epocas, revelando universalmente, e sempre, a natureza do homem e dos diversos agrupamentos por elle formados.

O direito é uma condição fatal, a que estão sujeitos, e de que visceralmente dependem, os organismos individuaes e sociaes.

Essa longa evolução de millenios, que vem do grupo patriarchal oriental até a sociedade mundial da actualidade, demonstra-o de sobejo e de modo irresistivel. E' explorando-a, pelos processos da logica scientifica, que a sociologia estabelece as duas leis fundamentaes, que servem de base, e base granitica, ao direito. Si não póde haver sociedade sem direito, o facto que todos observamos, e que ninguem nega, da existencia da sociedade mundial, é prova irrefragavel da existencia do direito respectivo, direito mundial, direito internacional. Eis ahi como a objecção se esborôa de encontro á base scientifica fundamental do direito. Quem diz sociedade mundial tem dito direito mundial.

\section{DisTINCÇ̃o ENTRE A MORAL E O DIREITO}

A distincção entre a moral e o direito nos offerece argumento de igual valor contra todas as objecções levantadas á existencia do direito internacional, como resulta facilmente do exame reflectido sobre a doutrina dessa distincção (conf. meus Ensaios, §14).

O facto de pagar o devedor sua divida, independentemente de pleito judicial, não implica negação, 
mas antes affirmação, do direito do seu credor. O facto de, por ausencia de força material, ficar sem execução a sentença proferida pelo juiz contra o devedor recalcitrante, não significa a inexistencia do direito creditorio nella affirmado, mas apenas que o credor não poude, por circumstancia occasional, tornar effectivo o seu direito.

As qualificações de justo e injusto, observa Spencer, pódem ser applicadas, mesmo sem um poder coercitivo.

Convém notar, de passagem, que justo é a denominação classica do direito, como explico nos Ensaios (Indice alphabetico, v. justo).

5. A OBJECCAO ATTINGE O DIREITO NACIONAL

Em summa: quem negar a existencia do direito internacional não poderá affirmar a existencia do direito nacional. São duas realidades positivas necessariamente coexistentes. 